\section{To collect or not to collect - a conservation issue?}

\section{Of shrikes and shrews}

The letter from Sir Christopher Lever in Oryx (26, 52-53) and the reply by Dr Hutterer highlight an important issue. There appears to be a growing, and mistaken, tendency to assume uncritically that the way to conserve wild animals is for no one to kill any of them or, to put it the other way round, that if no one kills any this will necessarily help conservation. It cannot be stated too clearly or too often that the way to conserve wild animals is to ensure that there is a viable population in a viable habitat. This is what counts, not the fate of individuals. Unadaptable species limited by specialized habitat requirements are, of course, particularly vulnerable.

Is it seriously suggested that removal of a few individuals from a shrew population by human agency would affect their conservation status one way or the other? Similarly, is one really expected to believe that release of the holotype of Laniarius liberatus after more than a year in captivity would contribute to the survival of the species?

Restriction or prohibition of killing certain wild animals may indeed be necessary, but only where such killing poses a threat to survival, usually in the form of over-exploitation for a commercially valuable product like fur, ivory, or meat. Clearly, this does not apply to small mammals of no commercial value whose vulnerability is to habitat loss and not to human predation.

Wildlife conservation requires knowledge of the species occurring and their biology. With African mammals we have still not even completed the primary species inventory, and in the last few decades collection of museum specimens has led to discovery of a quite remarkable number of previously unknown species. These are not all of shrew size - a new monkey from Gabon Cercopithecus solatus was discovered in 1984 and named in 1988. Continued investigation, including collection of study specimens, is essential for conservation to have the proper scientific basis, with- out which it can hardly hope to succeed.

W. F. H. Ansell, Trendrine, Zennor, St Ives, Cornwall TR26 3BW.

\section{Of shrikes, shrews and storm-petrels}

Some additional points deserve consideration in the debate initiated by Sir Christopher Lever and Rainer Hutterer about the collection of newly discovered shrikes and shrews (Oryx, 26, 52-53), which may be illustrated by considering another example of the treatment of a potential new bird.

Considerable public excitement has recently been caused around the north-east Atlantic by the observation, and sometimes capture, ringing or banding, and subsequent release unharmed, of a number of dark-rumped, forked-tailed storm-petrels resembling the eastern Asiatic form of Leach's storm-petrel, Oceanodroma (leucorhoa) monorhis (Swinhoe's storm-petrel), which winters in the Indian Ocean and may possibly have reached the Atlantic around South Africa (Birding World, 2, 288-289; 3, 27, 114, 151, 224-225, 249; 4, 230, 295-297, 335) although the birds are on average slightly larger and a number of photographs show unusually prominent pale primary-shafts, which suggested that they might also be a doubtless rare new North Atlantic representative of that form.

This presents a difficult conservation problem because under much current protective legislation species have to be named individually, so that until they have been described, proved to occur in an area, and entered on the appropriate schedule they receive no protection. Thus, it would currently appear to be perfectly feasible for some unscrupulous dealer to locate a breeding colony of a new British bird such as this petrel, collect them all, take their eggs, and offer them around the world for sale to less squeamish people at inflated prices as unique specimens of an extinct, undescribed British bird, without the possibility of any legal action to prevent it.

While the most detailed study of these birds (Ibis, 133, 351-356) concludes that they are indistinguishable from Swinhoe's stormpetrel, it fails to explain why pale primary- 
shafts are again present in an illustration. There has sometimes been a discussion when a bird was caught whether a primary ought to be retained when it was released, which should not have caused it much harm, but apparently so far nothing has been collected except blood and a tape-recording of its voice. Yet in spite of this caution apparently no arrangements have been made for the protection of this form anywhere in the North Atlantic area 10 years after it was first seen, nine years after it was first caught at a potential breeding site, and two-and-a-half years after the first of four captures in Britain.

One issue that has regularly arisen during this and other cases of the discovery of new birds with which I have been involved, some of which had only been overlooked so long because they proved to be among the rarest birds in the world, is that many academics are often remarkably slow to recognize new species, although until they have been described the legal authorities are seldom prepared to take much action to protect them. While it may now be fashionable to claim that it is possible to define new forms by reference to their voice, behaviour, or biochemistry, and these may indeed provide a useful guide to relationships, they do not reveal much else about an organism, such as its size, anatomy, or the colour of its primary shafts.

It may also be difficult for other people to carry out such studies in a comparable way, while any who have the experience, time and equipment may still find it difficult to complete comprehensive surveys quickly. While I oppose the slaughter of wildlife for fun, trophies, or to document distribution, it also seems important that the existence of any new forms, and most especially rare ones, which might disappear leaving insoluble mysteries, should be fully documented in all possible ways, including the preservation of anatomical material as soon as the opportunity arises.

These observations suggest a number of considerations: firstly, as recently stressed by the House of Lords Select Committee on Science and Technology in their first report on the decline of research on systematic biology in Britain (House of Lords Session 1991-92 HL
Paper 22-1), it needs to be understood that all biological studies are ultimately dependent upon the reliable classification of species, or taxonomy. In view of the growing delay in the identification of a variety of new birds when they appear in Britain, such as the stormpetrels discussed above, following the suspension of research on birds, among other groups, at the Natural History Museum, it seems time that there was more support for such studies.

Secondly, it needs to be more widely understood that while there is now a diminishing need for general collecting, it is still sometimes important for purposes of both conservation and the advancement of knowledge that examples of potential new forms should be placed on record as soon as possible, if only because it is often necessary to demonstrate their existence in order to secure their protection. While it is comprehensible that some may object to the idea of collecting animals at all (I do myself - it tends to be a most uninspiring procedure, and I have done little of it), it is not really helpful to the conservation of the species if there are ill-informed complaints whenever anyone attempts to prove their existence.

Thirdly, in view of the previous consideration it seems regrettable that those attempting to protect vanishing species so often seem strangely uninterested in preserving evidence for their character, including natural casualties, stray remains, old nests, addled eggs, field observations and local information, in case they are lost. It therefore needs to be agreed that if conservationists wish to limit collecting, they must encourage more vigorous attempts to preserve specimens that become available naturally. The local predators frequently leave remains around all over the place.

Fourthly, while there may still sometimes be a need for specimens, much care may be required in collecting them. Thus, while it may not harm a species to lose a few individuals, it may have a disastrous effect if, as has happened in some cases, local people are offered money to collect what they previously thought were valueless protected animals. Allowance should also be made for such phe- 
nomena as the disturbance of sex-ratios in declining populations, when, for example, if there are five males to every female it might cause little harm to take a male, but a disaster to take a female.

Finally, it seems time that much conservation legislation was revised to give better protection for potentially rare new forms while they are identified, perhaps by providing general protection for all harmless wildlife. In areas with restrictions on collecting anything at all, revision may also be needed to permit the preservation of natural casualties.

W. R. P. Bourne, 3 Contlaw Place, Milltimber, Aberdeen AB1 ODS, Scotland.

\section{Cows give badgers TB after all}

The badger-culling operations carried out in the UK in an attempt to eradicate bovine tuberculosis have failed to reduce the level of tuberculosis breakdowns in cattle herds in Britain since 1974 (Bovine Tuberculosis in Badgers. 15th Annual Report, Ministry of Agriculture, Fisheries and Food, October 1991). The reason is simple: badgers found to have TB after a herd breakdown contracted the disease from cattle, and not vice versa.

It has always been assumed that the 2 per cent of open-lesion infectious cattle are discovered by routine testing and removed before they have passed on TB to other cattle or badgers. But an average of 4.3 reactors/breakdown suggest some transmission between cattle as well as environmental contamination.

A largely forgotten French study a century ago showed that earthworms could carry viable bacilli, thus suggesting a very efficient transfer mechanism from cow to badger. Earthworms help to decompose cow pats, and earthworms make up 50 per cent of badger diet annually. Infection from this dietary route and head lymph nodes, rapidly becomes an apparent 'respiratory' case via the blood. Badger lungs often contain silica dust particles from living underground and the immunosuppressed lung tissue succumbs easily to TB. Even 6-month-old cubs may be acute TB cases.

Finding infected badgers some months after a bad herd breakdown is almost inevitable, given such an efficient transfer mechanism from cattle. Former blackspot counties in the Midlands have low levels in badgers and cattle, suggesting badger TB dies out when not topped up by recurring herd incidents. Culling badgers is hence totally unjustified on economic or scientific grounds.

M. Hancox on behalf of National Federation of Badger Groups, 72 Bisley Old Road, Stroud, Gloucestershire, GL5 1NB.

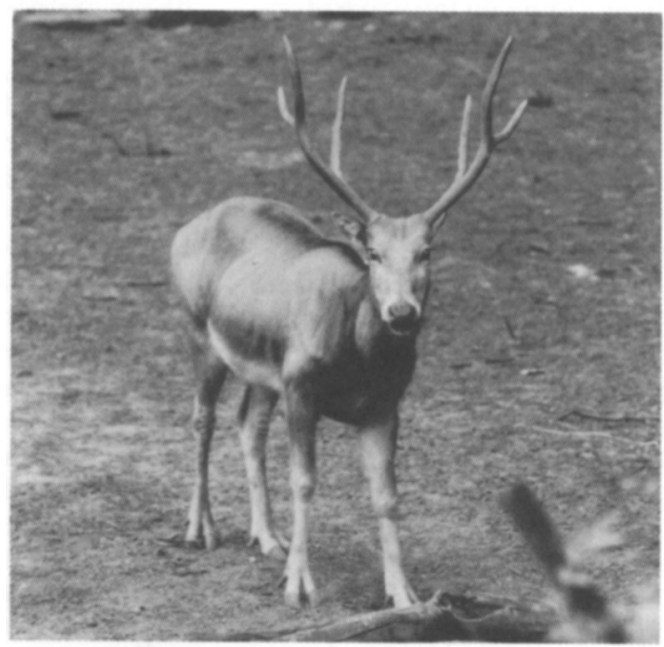

Père David's deer Elaphurus davidianus (WWF/F. Vollmar).

\section{Père David's deer}

During a recent visit to China I had a rare opportunity to see the flourishing herd of Père David's deer and so read the Briefly item on the deer reintroduction (Oryx , 26, 12) with interest. The deer live in Nan Haizi Milu Park, the former Imperial Deer Park situated some $60 \mathrm{~km}$ to the south of Beijing, and not in the grounds of the Imperial Palace. as your source states. As far as I know it was here that Père David noticed the deer in 1865 and managed to buy several from the official in charge. The first reintroduction, of 20 deer, in 1985, was augmented by a further 18 in 1986 . The park is run by the Beijing Milu Ecological Research Centre under Professor Wang Zongyi.

Richard Willan, Old Hill, Lurgashall, Petworth, Sussex GU28 9HB. 